Mado SM

Aikhionbare HA Akpede GO

\title{
Pattern and antimicrobial sensitivity of pathogens in acute bacterial meningitis beyond neonatal period at Ahmadu Bello University Teaching Hospital (ABUTH) Shika, Zaria
}

DOI:http://dx.doi.org/10.4314/njp.v40i1.13

Accepted: 23rd July 2012

Mado SM ( $\square)$

Aikhionbare HA

Department of Paediatrics,

Ahmadu Bello University Teaching

Hospital, Zaria, Nigeria

Email: sanimado@yahoo.co.uk

Tel: +2347037962150

Akpede GO

Department of Paediatrics,

Irrua Specialist Teaching Hospital,

Edo State. Nigeria

\begin{abstract}
The causative agents of acute bacterial meningitis vary from time to time and from place to place. In addition, changes in pathogen's sensitivity to antibiotics in use occur. The study was undertaken to identify the pattern and susceptibility of pathogens to antibiotics among children beyond neonatal period for prompt empirical treatment of this important cause of morbidity and mortality especially in developing countries.

Objective. To identify the pattern and susceptibility of pathogens in acute bacterial meningitis among children aged one month to 12 years at ABUTH Shika, Zaria.

Method: This was a prospective study carried out in children presenting to Emergency Pediatric Unit of ABUTH Shika, Zaria, from October $1^{\text {st }} 2005$ to September $30^{\text {th }}, 2006$. Children who met the inclusion criteria for lumbar puncture were consecutively recruited. Cerebrospinal fluid (CSF) samples were collected for microscopy, culture, sensitivity, and Latex Particle Agglutination (LPA) test. Sixty-six (66) patients satisfied the criteria for acute bacterial meningitis and were studied.

Results: The prevalence of acute bac-
\end{abstract}

terial meningitis in this study was $6.9 \%$. Sixty-six patients with acute bacterial meningitis were identified using 3 diagnostic methods (Gram stain, culture and LPA). The 3 commonest organisms were Streptococcus pneumoniae 34 (51.5\%), Haemophilus influenzae 18 (27.3\%), and Neisseria meningitidis 12 $(11.2 \%)$. The sensitivity of the isolates to three commonly used noncephalosporin antibiotics was chloramphenicol $74.4 \%$, penicillin $38.5 \%$, and ampicillin $2.6 \%$. The sensitivity to the cephalosporin was cefotaxime $97.4 \%$, and ceftriaxone $89.7 \%$ while that to Ofloxacin, a quinolone, was $100 \%$.

Conclusion: The three commonest bacterial agents causing post neonatal meningitis were Streptococcus pneumoniae, Haemophilus influenzae, and Neisseria meningitidis. There is an increasing resistance to the three commonly used noncephalosporin antibiotics (chloramphenicol, ampicillin and penicillin) and hence, cefotaxime or ceftriaxone should be used in the empirical treatment of children with suspected acute bacterial meningitis beyond neonatal period.

\section{Introduction}

Acute bacterial meningitis is an important cause of morbidity and mortality throughout the world. ${ }^{1}$ It is among the commonest neurological disorders in children in the tropical countries. ${ }^{2}$ it is of note that the disease remains a significant cause of morbidity and mortality in many developing countries despite advances in medical treatment. $^{2,3}$ it has been observed that many pathogens can cause meningitis, but however, Haemophilus influenzae was reported to be the common cause in infancy and toddler-age group in pre-Hib (Haemophilus influenzae type b) vaccine era. ${ }^{4,5}$ The predominance of Hib in infancy and toddlers in pre Hib vaccine era was more in developed countries, whereas reports from African studies including Nigeria found Streptococcus pneumoniae and Neisseria meningitidis as the two most important pathogens. $^{6}$

The causative agents of meningitis varies from place to place and alsotheir antibiotic susceptibility and therefore knowledge of the locally predominant organisms in different age groups and their sensitivity pattern is essential for effective chemotherapy. Furthermore,for a poten- 
tially fatal infection like childhood meningitis,the need for periodic assessment of the continuing sensitivity of the causative agents to antimicrobial in use is necessary. This is particularly necessary especially where non- existenceof rapid investigative modalities leave the clinician with no choice but to initiate empirical treatment. The objectives of the current study were therefore, to identify the pattern and antimicrobial sensitivity of pathogens in acute bacterial meningitis beyond neonatal period at ABUTH Shika, Zaria.

\section{Subjects and Methods}

The study was conducted in the Emergency Pediatric Unit (EPU) of ABUTH Shika, Zaria from October $1^{\text {st }}$ 2005 to September $30^{\text {th }}, 2006$. The approval of ABUTH Shika, Zaria Ethical Committee was sought for and obtained before the commencement of the study. Also informed parental/Care giver consent was sought before lumbar puncture (LP).Children aged one month to 12 years with suspected acute bacterial meningitis had LP. The criteria for LP for children $<18$ months are as follows: presence of fever and convulsion with or without either vomiting, irritability, loss of consciousness, and/ or bulging anterior fontanelle while for children $>18$ months, LP was done in the presence of: (a) fever and convulsion plus presence or absence of typical signs of meningeal irritation (defined by neck stiffness, positive Kernig's and/ or Brudzinski's sign), (b) fever without convulsion plus typical signs of meningeal irritation. For the purpose of this study, acute bacterial meningitis was defined as the presence of at least one of the following features: bacterial growth on CSF culture, positive CSF Latex Particle Agglutination (LPA) or an organism seen on Gram stain of CSF. ${ }^{7}$ The CSF samples collected in the sterile bottles were subjected to standard Microbiology culture, sensitivity, and Gram staining technique. ${ }^{8}$ CSF culture was regarded as the gold standard method for the diagnosis of acute bacterial meningitis. The inclusion of LPA in the diagnostic methods in this study was done to improve the diagnostic yield as culture of some of the bacterial agent from CSF can be difficult because of their fastidious nature. Also LPA was included in the diagnostic method because the results of CSF Gram stain and culture may be altered by prior use of antibiotics, a common problem in developing countries. ${ }^{9}$ The LPA test was performed on CSF supernatant using PASTOREX MENINGITIS according to the manufacturer's instruction (BIO-RAD France). The test kits can identify Neisseria meningitidis, Haemophilus influenzae, Streptococcus pneumoniae, Streptococcus group B, and Escherichia coli. The sensitivity of the test kits reagent was $70 \%$ to $90 \%$ while specificity was $95 \%$. The CSF supernatant was heated for 3 minutes at $100^{\circ} \mathrm{C}$ in order to denature CSF proteins and to prevent nonspecific agglutination and was then centrifuged at 17000 revolutions per minute (rpm) for five minutes. The reagents were shaken and one drop (30 microlitre) of each dispensed to corresponding reaction fields on the latex agglutination card and in the two wells of the two plastic reactions slides. Each card has seven reaction fields corresponding to the reagents. Forty microlitre of test specimen was dispensed to each field and thoroughly mixed using the stirrer (supplied with the kits) for each field the mixture covered the entire field completely. For the plastic reaction slides, it was ensured that the latexsample mixture migrated into the capillary of each slide. The result was read within 10 minutes. A uniform white precipitate appearing in only the reaction field was considered positive, indicating the presence of antigen of the corresponding organism. The test was considered negative if the mixture remained homogenous.

Data collected were entered into computer and Epi-info version 3.3.2 was used for analysis. Simple tables were drawn for the frequencies and percentages. Chi -square test was used for comparison of proportions. A p-value $<0.05$ was considered statistically significant.

\section{Results}

Sixty-six patients who met the inclusion criteria were studied. During the study period, 956 children aged one month to 12 years were admitted into EPU. The prevalence of bacterial meningitis was $6.9 \%$ (66 of 956). Thirty-nine $(59.1 \%)$ patients were males and 27 (40.9\%) females. The ages ranged from one month to 12 years with a mean age (+_1 SD) of $42.7+\_41.3$ months. The male to female ratio (M: F) was 1.4:1.

\section{Infections and age}

The distribution of patients with acute bacterial meningitis by age is shown in table 1 . Twenty-seven (40.9\%) of the 66 patients with acute bacterial meningitis were infants, $20(30.3 \%)$ were aged 13 months to four years while $19(28.8 \%)$ were above four years of age.

Table 1: Distribution of cases of acute bacterial meningitis in 66 patients by age.

\begin{tabular}{lll} 
Age in months & Frequency & Percentage \\
\hline $1-2$ & 6 & 9.1 \\
$3-12$ & 21 & 31.8 \\
$13-24$ & 6 & 9.1 \\
$25-48$ & 14 & 21.2 \\
$49-144$ & 19 & 28.8 \\
Total & 66 & 100 \\
\hline
\end{tabular}

Pathogens and age

The distribution of pathogens in CSF was Streptococcus pneumoniae 34 (51.5\%), Haemophilus influenzae 18 (27.3\%), Neisseria meningitidis 12 (18.2\%), Escherichia coli $1(1.5 \%)$, and Enterobacter specie $1(1.5 \%)$. Eleven (32.4\%) of pneumococcus and 12 of Haemophilus influenzae occurred during infancy while only 2 (16.7\%) cases of Neisseria meningitidis were present during infancy. 


\begin{tabular}{|c|c|c|c|c|c|c|}
\hline \multirow[b]{2}{*}{ Organisms } & \multirow[b]{2}{*}{$1-2$} & \multicolumn{4}{|c|}{ Age groups (months) } & \multirow[b]{2}{*}{ Total(\%) } \\
\hline & & $3-12$ & $13-24$ & $25-48$ & $49-144$ & \\
\hline $\begin{array}{l}\text { Streptococcus } \\
\text { pneumoniae }\end{array}$ & 1 & 10 & 5 & 10 & 8 & $34(51.5)$ \\
\hline $\begin{array}{l}\text { Haemophilus } \\
\text { influenzae }\end{array}$ & 3 & 9 & 1 & 3 & 2 & $18(27.3)$ \\
\hline $\begin{array}{l}\text { Neisseria } \\
\text { meningitidis }\end{array}$ & - & 2 & - & 1 & 9 & $12(18.2)$ \\
\hline $\begin{array}{l}\text { Escherichia } \\
\text { coli }^{*}\end{array}$ & 1 & - & - & - & - & $1(1.5)$ \\
\hline $\begin{array}{l}\text { Enterobacter } \\
\text { species** }\end{array}$ & 1 & - & - & - & - & $1(1.5)$ \\
\hline Total & 6 & 21 & 6 & 14 & 19 & $66(100)$ \\
\hline
\end{tabular}

*Isolated in a 6- week old infant

** Isolated in a 2- month old infant

\section{Laboratory diagnosis}

The result of the three methods used to identify the aetiological agent in CSF of 66 patients is shown in table 3. LPA detected $53(80.3 \%)$ of 66 agents in CSF, Gram stain identified $47(71.2 \%)$ and CSF culture isolated $39(59.1 \%)$ organisms. Among the 13 (19.7\%) agents missed by LPA, Gram stain detected 11 organisms while culture yielded two. The $27(40.9 \%)$ cases that are negative by CSF culture were positive by LPA (18) and Gram stain (9).

Table 3: Results of the 3 methods used to identify the aetiological agents in the CSF of 66 patients.

\begin{tabular}{lll} 
Method & $\begin{array}{l}\text { Positive } \\
\text { No. }(\%)\end{array}$ & $\begin{array}{l}\text { Negative } \\
\text { No. }(\%)\end{array}$ \\
\hline Gram stain & $47(71.2)$ & $19(28.8)$ \\
LPA & $53(80.3)$ & $13(19.7)$ \\
Culture & $39(59.1)$ & $27(40.9)$ \\
\hline
\end{tabular}

Relationship between CSF culture, Gram stain, LPA, and the use of antibiotics before presentations

A history of use of antibiotics before presentation was obtained in $30(45.5 \%)$ of 66 patients.Among the 30 patients on antibiotics before presentation 13, 12 and 24 were positive for culture, Gram stain and LPA respectively. There was a statistically significant relation between the use of antibiotics before presentation and negative CSF culture(13/39 (33.3\%) versus $17 / 27$ $\left.(62.7 \%) ; \mathrm{x}^{2}=4.52, \mathrm{p}=0.03\right)$ and Gram stain $(12 / 47$ $(25.5 \%)$ versus $\left.18 / 19(94.7 \%) ; x^{2}=14.04, p=0.00\right)$ while LPA was not affected by prior use of antibiotics ( $24 / 53(45.3 \%)$ versus $6 / 13(46.2 \%) ; x^{2}=0.06, p=$ $0.79)$.

\section{Sensitivity of the pathogens to antibiotics}

The sensitivity pattern of the 39 bacterial isolates from CSF culture to antibiotics is shown in table 4.
Table 4: CSF bacterial isolates and their in-vitro antibiotic sensitivity rates.

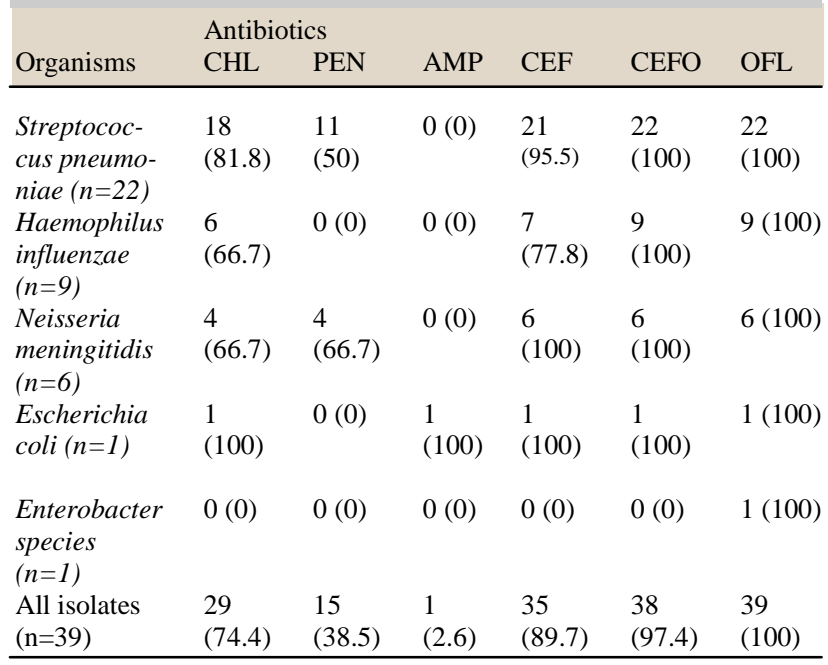

Figures shown as no. (\%) sensitive.

CHL - Chloramphenicol PEN - Penicillin CEF - Ceftriaxone

$\mathrm{CEFO}-$ Cefotaxime $\quad \mathrm{AMP}-$ Ampicilin $\quad \mathrm{OFL}-$ Ofloxacin

The sensitivity rate was highest to Ofloxacin 39 (100\%) followed by cefotaxime $38(97.4 \%)$ and ceftriaxone 35 (89.7\%). It was moderate to chloramphenicol 29 (74.4), and lowest to ampicillin one (2.6\%) and penicillin 15 $(38.5 \%)$. The sensitivity of pneumococcus to penicillin and chloramphenicol were $50 \%$ and $81.8 \%$ respectively while that to ceftriaxone and cefotaxime were $95 \%$ and $100 \%$. The isolates of Neisseria meningitidis had a sensitivity rate of $66.7 \%$ to both chloramphenicol and penicillin. Thirty-eight $(97.4 \%)$ of the total isolates were resistant to ampicillin. All the isolates of Haemophilus influenzae were resistant to ampicillin and penicillin while sensitivities to cefotaxime, ceftriaxone and chloramphenicol were $100 \%, 77.8$, and $66.7 \%$ respectively.

Outcome: Eight (12.1\%) of 66 patients died while $16(24.2 \%)$ had neurologic sequelae.

\section{Discussion}

The prevalence of acute bacterial meningitis in this study was $6.9 \%$. This is similar to the prevalence of $6.2 \%$ reported from Ibadan. ${ }^{10}$ However, the prevalence was higher than the ones reported from Shagamu $(2.8 \%),{ }^{3}$ Maiduguri $(3.5 \%),{ }^{9}$ Enugu $(3.1 \%),{ }^{11}$ and more recently from Ilesa $(1.6 \%) .{ }^{12}$ The lower prevalence in Shagamu as well as in others ${ }^{10,11,12}$ may be due to the differences in methodology. The prevalence of childhood bacterial meningitis over a time frame in Nigeria seems to be decreasing. The exact reason for the relative decrease in the prevalence of childhood meningitis in Nigeria is not known. In developed countries there is a decline in the overall prevalence of meningitis as a result of reduction in the prevalence of Hib infection due to Hib vaccine introduction and this vaccine was yet to be available widely in Nigeria.This study has shown that meningitis is commoner in males than females. The 
male preponderance $(1.4: 1)$ in this study agrees with the finding of other workers in developing countries. Okoroma and Izuora, ${ }^{13}$ found a male to female ratio of 1.3:1. Olanrewaju et al in Shagamu found a male to female ratio of 2.1:1. The male preponderance may be due the relative absence of a gene locus for elaboration of immunoglobulin, which was said to be located on the x chromosomes. $^{14}$

Infants accounted for $27(40.9 \%)$ of the total patients with meningitis in this study. This finding is similar to what has been reported previously. ${ }^{10,15,16}$ The incidence of meningitis in this age group may be partly due to the vulnerability of their choroid plexus to penetration by bacteria during the septicaemic process, and to low immunological status.

The major organism detected in the present study was Streptococcus pneumoniae, which accounted for $51.5 \%$ while Haemophilus influenzae was the second most common pathogen accounting for $27.5 \%$ and Neisseria meningitidis accounted for $18.2 \%$. This pattern is in contrast to that reported ${ }^{9}$ from Maiduguri in northeastern Nigeria were Neisseria meningitidis was the most common cause of sporadic cases of meningitis accounting for $36 \%$ of the total isolates while Streptococcus pneumoniae occurred in $29.3 \%$ of cases. However, the pattern of predominance of Streptococcus pneumoniae in this study was not different from reports from other centres in Nigeria ${ }^{3,10,12,15}$ and elsewhere. ${ }^{5,6,16}$ Cerebrospinal fluid culture is the gold standard for the diagnosis of bacterial meningitis but use of antibiotics prior to presentation can significantly reduced the positivity of both CSF culture and Gram stain as shown in this study. Latex particle agglutination test may overcome the limitation of CSF culture, as bacterial antigens in CSF are not significantly affected by prior antibiotics use. LPA test detected more cases $(80.3 \%)$ than culture $(59.1)$ or Gram stain $(71.2 \%)$. Despite its limitations of intra specie and inter specie cross reactions, ${ }^{17}$ the test has utility value as result can be obtained within 15 minutes. There is high rate of in-vitro resistance to 2 (ampicillin and penicillin) of the three (ampicillin, penicillin and chloramphenicol) commonly used antibiotics. Overall, the sensitivity of isolates to ampicillin was $2.6 \%$, penicillin $38.5 \%$, chloramphenicol $74.4 \%$, cefotaxime $97.4 \%$, ceftriaxone $89.7 \%$, and Ofloxacin $100 \%$.

The relatively free access to antibiotics from patent medicine store might be contributory to the high rates of resistance to penicillin and ampicillin. The $74.4 \%$ susceptibility rate of isolates to chloramphenicol in this study was lower than the $89.3 \%$ reported from Maiduguri. ${ }^{9}$ The high rates sensitivity to cefotaxime (97.4\%) and ceftriaxone $(89.7 \%)$ agrees with previous report from Libya. ${ }^{16}$ The low resistance to the cefotaxime and ceftriaxone might be due to their restricted use owing to their high cost which majority of parents could not afford. The high rate of susceptibility (100\%) of organisms to Ofloxacin, a quinolones in this study may be because they are rarely used in children in view of their potential to cause damage to the growing cartilage in these age groups. The high rate $(50 \%)$ of pneumococcal resistance to penicillin found in this study is comparable to that reported previously from Nigeria ${ }^{9,12}$ and Kenya. ${ }^{18}$ The sensitivity rate of Neisseria meningitides to penicillin in this study is low $(66.7 \%)$. The $81.8 \%$ pneumococcal sensitivity to chloramphenicol is also similar to that in previous reports from Nigeria. ${ }^{3,10,12,15}$ There was an occasional report from Nigeria, describing a low $(30.8 \%)$ sensitivity of pneumococcus to chloramphenicol. ${ }^{19}$ The sensitivity rate of both Haemophilus influenzae and meningococcus to chloramphenicol was $66.7 \%$ each.

The mortality rate of $12.7 \%$ in this study compares favourably with what was obtained in some reports from Nigeria $^{3}$ and Libya. ${ }^{16}$ The overall neurologic sequelae rate of $24.2 \%$ is similar to that reported by Olanrewaju et $\mathrm{al}^{3}$ from Shagamu, Nigeria, but however, much higher than the report from Enugu ${ }^{11}$ and more recently from Ilesa. $^{12}$

\section{Conclusion}

The finding of high rate of resistance to ampicillin and penicillin in this study does not support the continued use of the combination of chloramphenicol with either penicillin or ampicillin for empirical treatment of acute bacterial meningitis and hence, cefotaxime or ceftriaxone should be commenced pending the outcome of CSF culture result. Also LPA should be included in the initial evaluation of CSF of children with suspected meningitis.

\section{Limitation of the study}

The sample size was too small to describe the sensitivity pattern.

Conflict of interest: None

Funding: None.

\section{Acknowledgements}

We wish to thank the Doctors and Nurses in the Department of Paediatrics for their efforts during the management of these patients. Special thank also goes to the staff of the Departments of Medical Microbiology, Haematology, and Immunology for their assistance during the study. 


\section{References}

1. Bell WE. Bacterial meningitis. Pediatr Clin North Am 1992; 39: 651-667.

2. Izuora GI. Inflammatory Diseases of the Central Nervous System. In: Azubuike JC, Nkanginieme KEO (eds). Paeditrics and Child Health in a Tropical Region. Owerri.African Educational Series, 1999: 362-399.

3. Olanrewaju DM, Olusanya $\mathrm{O}$, Laditan AAO. Acute bacterial meningitis in children. West Afr J Med 1991; 10: 405-411.

4. Prober CG. Acute bacterial meningitis beyond the neonatal period. In: Behrman RE, Kliegman RM, Jenson HB (eds). Nelson Textbook of Pediatrics. $16^{\text {th }}$ ed. Philadelphia. WB Saunders, 2000: 751757.

5. Commey JOO, Rodrigues OP, Akita FA et al. Bacterial meningitis in children in Southern Ghana. East Afr Med J 1994; 71: 113117.

6. Mackie EJ, Shears P, Frimpong E et al. A study of bacterial meningitis in Kumasi, Ghana. Ann Trop Paediatr 1992; 12: 143-148.

7. Berkley JA, Mwangi I, Ngetsa CJ, et al. Diagnosis of acute bacterial meningitis in children at a district hospital in Sub-Saharan Africa. Lancet 2001; 357:1753-1756.
8. Chessbrough M. Medical Laboratory Manual for Tropical Countries, Vol. 2. London Butterworth, 1988: 26-205.

9. Akpede GO, Adeyemi O, Abba AA et al. Pattern and antibiotic susceptibility of pyogenic meningitis in Maiduguri, Nigeria, 19881992. Acta Paediatr1994; 83: 719 . 723.

10. Alausa OK, Onile BA. The pattern of bacterial meningitis in Ibadan (A 21-month prospective study). Niger Med J 1984; 14: 167-170.

11. Ojinaka NC, Iloeje SO. Neurological complications of childhood bacterial meninigitis as seen in Enugu. Niger J Paed 1998; 25: 53 56.

12. Ogunlesi TA, Okeniyi JAO, Oyela$\mathrm{mi}$ OA. Pyogenic meningitis in Ilesa, Nigeria. Indian Pediatrics 2005; 42(17): 1019-1023.

13. Okoroma EO, Izuora GI. Bacterial meningitis in children at Enugu. Niger J Paed1986; 13: 35-40.

14. Washburn TC, Medearis DN Childs B. Sex differences in susceptibility to infections. Pediatrics 1965; 35: 57-64.
15. Alausa OK, Osoba BA. Aetiology of acute bacterial meningitis in Ibadan. Niger J Paed 1974; 1: 5763.

16. Shembesh NM, El-Bargathy SM, Rao BN et al. A prospective study of bacterial meningitis in children from north-eastern Libya. Ann Trop Paediatr 1998; 18: 203-207.

17. Whittle HL, Egler LJ, Tugwell $P$ et al. Rapid bacteriological diagnosis of pyogenic meningitis by Latex Agglutination. Lancet 1974; 57: 619-621.

18. Wamola IA, Mirza NB, Nsanzumuihire H. Penicillin-resistant pneumococcal meningitis in Kenyatta National Hospital, Nairobo, Kenya. East Afr Med J1981; 58: 12-17.

19. Johnson WBR, Adedoyin OT, Abdulkarim AA, et al. Bacterial pathogens and outcome determinants of childhood pyogenic meningitis in Ilorin, Nigeria. Afr J Med Sci 2001; 30: 295-303. 